\title{
Effect of Thin-Film Coating on Wear in EGR-Contaminated Oil ${ }^{*}$
}

\author{
Oyelayo O. Ajayi, Saud H. Aldajah, Ali Erdemir, and George R. Fenske \\ Energy Technology Division \\ Argonne National Laboratory \\ Argonne, IL 60439
}

\begin{abstract}
The submitted manuscript has been created by the University of Chicago as Operator of Argonne National Laboratory under Contract No. W-31-109-ENG-38 with the U.S. Department of Energy.

The U.S. Government retains for itself, and others acting on its behalf, a paid-up, nonexclusive,

irrevocable worldwide license in said article to reproduce, prepare derivative works, distribute

copies to the public, and perform publicly and display publicly, by or on behalf of the

Government.
\end{abstract}

October 2001

Manuscript of paper to be presented at 2002 SAE Future Car Congress, Arlington, VA, June 3-5, 2002.

\footnotetext{
*Work supported by the Department of Energy, Office of Transportation Technology, under Contract W- 31-109-Eng-38.
} 


\title{
Effect of Thin-Film Coating on Wear in EGR-Contaminated Oil ${ }^{*}$
}

\author{
Oyelayo O. Ajayi, Saud H. Aldajah, Ali Erdemir, and George R. Fenske \\ Energy Technology Division \\ Argonne National Laboratory \\ Argonne, IL 60439 \\ Phone (630) 252-9021 \\ Fax (630) 252-4798 \\ ajayi@anl.gov
}

\begin{abstract}
:
Increased use of higher-efficiency compression ignition direct injection (CIDI) diesel engines instead of today's gasoline engines will result in reduced fuel consumption and greenhouse gases emissions. However, $\mathrm{NO}_{\mathrm{x}}$ and particulate exhaust emissions from diesel engines must be significantly reduced due to their possible adverse health effects. Exhaust gas recirculation (EGR) is an effective way to reduce $\mathrm{NO}_{\mathrm{x}}$ emissions from diesel engines, but the particulates and acidic exhaust products in the recirculated gas will contaminate engine lubricant oil by increasing the soot content and total acid number (TAN). These factors will increase the wear rate in many critical engine components and seriously compromise engine durability. We have investigated the use of commercially available thin and hard coatings (TiN, TiCN, TiAlN, and $\mathrm{CrN}$ ) to mitigate the negative effects of EGR on wear. In tests with the four-ball machine according to ASTM D4172, we found that all the four coatings deposited on M-50 steel significantly reduced wear in EGR-contaminated oils when compared with uncoated M50 steel balls.
\end{abstract}

\footnotetext{
*Work supported by the Department of Energy, Office of Transportation Technology, under Contract W- 31-109-Eng-38.
} 


\section{Introduction:}

The widespread use of compression ignition direct injection (CIDI) diesel engines in automotive and truck vehicles will have a major economic and environmental impact. Because of the higher efficiency of the CIDI engines, their use will result in significant reduction in both fuel consumption and consequently greenhouse gases emission. An estimate of as much as $30-35 \%$ reduction in greenhouse gases has been predicted as a result of this fuel consumption reduction [1] from CIDI diesel engines. Lower fuel consumption will also translate to less dependence on foreign oil, which has both economic and national security implications.

A major obstacle to the commercialization of CIDI diesel engines, especially for automotive applications, is their high level of $\mathrm{NO}_{\mathrm{x}}$ and particulate emissions, both of which have possible negative effects on health. Major efforts by both government (U.S. Department of Energy) and industry are thus currently being directed at development of technologies to reduce diesel engine emissions.

An effective means of reducing $\mathrm{NO}_{\mathrm{x}}$ emissions in both spark ignition and diesel engines is exhaust gas recirculation (EGR) $[2,3]$. Oxides of nitrogen $\left(\mathrm{NO}_{\mathrm{x}}\right)$ are formed when the combustion chamber temperatures are too high. Any measure that reduces the combustion temperature will lead to reduction in $\mathrm{NO}_{\mathrm{x}}$ formation and emission. EGR involves recirculation of exhaust gas into the intake stream. The recirculated gas displaces some of the normal intake charge, which slows and cools the combustion process, thereby reducing $\mathrm{NO}_{\mathrm{x}}$ formation. However, recirculation of exhaust product back into the engine combustion chamber has detrimental effects. Engine durability is compromised by EGR due to oil contamination by engine exhaust products $[4,5]$. 
The use of EGR increases the soot and particulate loading of the lubricant oil. This is expected to increase the abrasive wear rate in critical engine components. Re-introduction of the acidic exhaust gas product (sulfuric acid) into the engine will rapidly increase the total acid number (TAN) of the lubricant. This will also increase the corrosive wear rate of various engine components. The accelerated rate of lubricant oil degradation and the resultant accelerated wear would require relatively short oil drain intervals. This goes against the current desire for extended oil drain interval in diesel engines.

One possible way to mitigate the detrimental effects of EGR on engine components is surface engineering. Because EGR accelerates abrasive and corrosive wear, application of a hard and corrosion-resistant layer on pertinent component surfaces should provide some protection in the tribologically aggressive EGR environment. Such a surface can be created by the deposition of hard, thin-film coatings on the engine component surfaces. Advantages of the application of thin-film over thick coatings, (for example by thermal spray) include no post-coating processing required, better dimensional tolerances of coated parts, and minimum design changes, if any, to the engine components.

This paper presents our preliminary investigation of the effect of commercially available thin-film coatings on the friction and wear behavior of steel surfaces when tested in EGR-contaminated diesel engine oil. The results will be employed to provide input for the development of hard, corrosion-resistant coatings for the EGR engine environment.

\section{Experimental Details:}

\section{Coatings:}


Tests were conducted with four different hard thin-film coatings, namely titanium nitride (TiN), titanium carbo-nitride (TiCN), titanium aluminum nitride (TiAlN), and chromium nitride $(\mathrm{CrN})$. All the coatings were deposited on $127 \mathrm{~mm}(0.5-\mathrm{in}$.) diameter hardened M-50 balls. All the coatings were deposited by a commercial coating producer, using physical vapor deposition (PVD) technique. Table 1 shows some properties of the coatings tested. The uncoated M50 balls have a Vickers a hardness of about 720 VHN (60 $\mathrm{Rc})$.

\section{Test Oil:}

Used diesel engine oil taken from a MACK T-10 engine test with EGR was used as lubricant for friction and wear testing. Some properties of the used oil were characterized prior to testing, (Table 2). As expected, the TAN is significantly higher than the TBN of the test oil, due to recirculation of acidic exhaust product by EGR. Similarly the soot content of 9.4\% is also significantly high, but expected with EGR.

\section{Friction and Wear Testing}

Uncoated and coated M50 balls were tested by using a four-ball test device.

Schematic of the test contact configuration is shown in Figure 1. It consists of a rotating ball loaded against three stationary balls. Adequate oil was added during each test such that the contact points on each of stationary balls were completely submerged in the test oil.

Tests were conducted with four balls of the same material type for a duration of 1 hour, with a load of $73 \mathrm{~N}(16.4 \mathrm{lb})$ and speed of $1200 \mathrm{rpm}$. All the tests were conducted at room temperature, although a significant temperature increase occurred during each test. No 
attempt was made to control the temperature. The friction coefficient was continuously monitored during each test. After each test, the wear scar dimensions on the stationary balls were measured with an optical microscope.

\section{$\underline{\text { Results and Discussion: }}$}

Figure 2 shows the variation of friction coefficient during the test for each of the material tested. Except for $\mathrm{CrN}$, all the tested coatings reduced the friction coefficient in the early part of the test (the first 10 minutes) when compared to the uncoated surface. $\mathrm{CrN}$ provided only a slight reduction, and only for a short duration (about the first 2 minutes). This initial frictional behavior perhaps reflects how the ball materials in sliding contact interact with the solid particles (soot) present in the oil. The harder coatings showed the lowest friction coefficient, which may be due to minimal ploughing contribution to friction. In the softest coating tested $(\mathrm{CrN})$ and the uncoated ball, ploughing by abrasive soot particles is expected to contribute more to friction, resulting in the higher initial friction coefficients in tests with these two materials.

By the midpoint of testing, the friction coefficients for all the test pairs were roughly the same at about 0.14 , except for the $\mathrm{CrN}$ coating, in which the friction coefficient remained relatively high at 0.21 . The friction coefficients are similar because the coatings were worn through by this point in the test, and the sliding was essentially that of steel-on-steel. The higher friction coefficient for the $\mathrm{CrN}$ coating is not fully understood at this time.

The average wear scar diameter on the stationary balls is shown in Fig. 3. All the thin-film coatings reduced the wear substantially. The harder coatings reduced the wear scar diameter by a factor of 2 to 3 which translates to a factor 16 to as high as 80 reduction in wear volume. The softer coating $(\mathrm{CrN})$ also reduced wear substantially, in spite of its higher 
friction when compared to the uncoated surface. The CrN coating reduced the wear volume by about a factor of 5 .

Figure 4 shows optical micrographs from the wear scar on the stationary balls. As indicated previously, all the coatings were worn through at the conclusion of each test. In all cases, abrasive wear was the dominant material removal mechanism. This was evident by the pronounced grooves and scratches in the direction of sliding observed on all the balls. However, the grooves and scratches are much larger and deeper in the uncoated M50 ball (Fig. 4a) compared to balls with harder coatings (Figs. 4b and 4d). In the coated samples there is also more produced evidence of oxidative wear mode (as indicated by dark patches on the wear track). This wear mode is much milder and often does not result in increased surface roughness.

In this study, the main wear mode is abrasive wear. This is due to the presence of significant amount of soot particles in the oil. The observation is also consistent with other previous studies [e.g.,6, 7]. Consequently, the higher hardness of the various thin-film coatings reduced the depth of penetration of the abrasive particles. This reduced the amount of material removed by the abrasive particles and, hence, the total amount of wear. The lowest amount of wear occurred with the TiN coating, even though it did not have the highest hardness. This may be due to more oxidative wear mode, which results in less material removal, with the TiN coating.

Results of this study showed that a hard thin-film coating can indeed mitigate accelerated abrasive wear in engine components caused by soot loading of lubricant oil with the EGR application. The impact of increased acidity of the oil cannot be clearly assessed in the present study. A long-term test may be required for such assessment. The current test configuration is a quick screening test to evaluate the potential application of a hard thin-film 
coating. More testing with the appropriate configuration for engine components of interest is still needed.

\section{Summary:}

The present study evaluated the effect of commercially available, hard, thin-film coating on wear of M50 material in a used oil from a diesel engine test with EGR. As expected, the EGR resulted in a significant amount of soot loading of the oil, and increased the acidity as well. In a four-ball wear test, all the four thin-film coatings evaluated reduced the wear significantly. Abrasive wear mode was the main wear mechanism, and consequently, harder coatings showed more improvement in the friction and wear performance of the surface. The results from this study suggest that hard thin-film coatings have the potential of mitigating the detrimental effect of EGR on the wear of diesel engine components. More work and more appropriate testing is still required to confirm this potential.

\section{Acknowledgment:}

This work was supported by the U.S. Department of Energy, Office of Transportation Technology. Used diesel engine oil with EGR was kindly supplied by Ralph Cherrillo of Equilon Lubricants.

\section{$\underline{\text { References: }}$}

1 C. J. Morey and J. Mark, "Diesel Passenger Vehicles - Can They Meet Air Quality Needs and Climate Change Goals,” SAE Technical Paper \# 2000-01-1599 (2000). 
2 R. C. Yu and S. M. Shahed, "Effect of Injection Timing and Exhaust Gas Recirculation on Emissions from a D.I. Diesel Engine," SAE Technical Paper \# 811234, (1981).

3 S. Tullis and G. Greeves, "Improving $\mathrm{NO}_{\mathrm{x}}$ Versus BSFC with EUI 200 Using EGR and Pilot Injection for Heavy-Duty Diesel Engines,” SAE Technical Paper \# 960843, (1996).

4 A. J. Dennis, C. P. Garner, and D. H. Taylor, “The Effect of EGR on Diesel Engine Wear," SAE Technical Paper \# 1999-01-0839, (1999).

5 M. Gautam, K. Chitoor, M. Durbha, and J. C. Summers, "Effect of Diesel Soot Contaminated Oil on Engine Wear - Investigation of Novel Oil Formulations," Tribology International, 32, (1999), 687-699.

6 H. Sato, N. Tokuoka, H. Yamamoto, and M. Sasaki, "Study of Wear Mechanism by Soot Contaminated Engine Oil,” SAE Technical Paper \# 1999-01-3573, (1999).

7 R. Mainwaring, "Soot and Wear in Heavy Duty Diesel Engines," SAE Technical Paper \# 971631, (1997).

Table 1: Some Properties of Thin-Film Coatings

Coating Deposition Method Thickness $(\mu \mathrm{m}) \quad$ Microhardness $\left(\mathrm{HV}_{0.05}\right)$ 


\begin{tabular}{cccc}
\hline TiN & PVD & 2 & 2700 \\
TiCN & PVD & 2 & 2800 \\
TiAlN & PVD & 2 & 3600 \\
CrN & PVD & 2.5 & 1800 \\
\hline
\end{tabular}

Table 2: Some Properties of Test Oil Lubricant

\begin{tabular}{|l|l|}
\hline Viscosity at $40^{\circ} \mathrm{C}$ & $176 \mathrm{cSt}$ \\
\hline Viscosity at $100^{\circ} \mathrm{C}$ & $19.83 \mathrm{cSt}$ \\
\hline Total Acid Number (TAN) & $5.78 \mathrm{mg} \mathrm{KOH} / \mathrm{g}$ \\
\hline Total Base Number (TBN) & $0.06 \mathrm{mg} \mathrm{KOH} / \mathrm{g}$ \\
\hline Soot Content (by TGA) & $9.4 \%$ \\
\hline
\end{tabular}




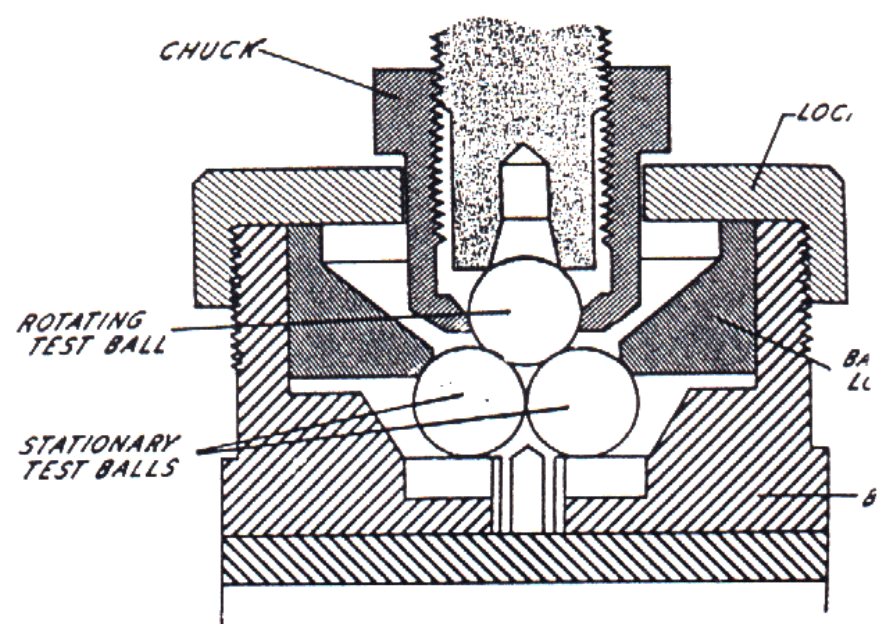

Figure 1: Schematic of four-balls test configuration

Friction Coefficient vs. Time

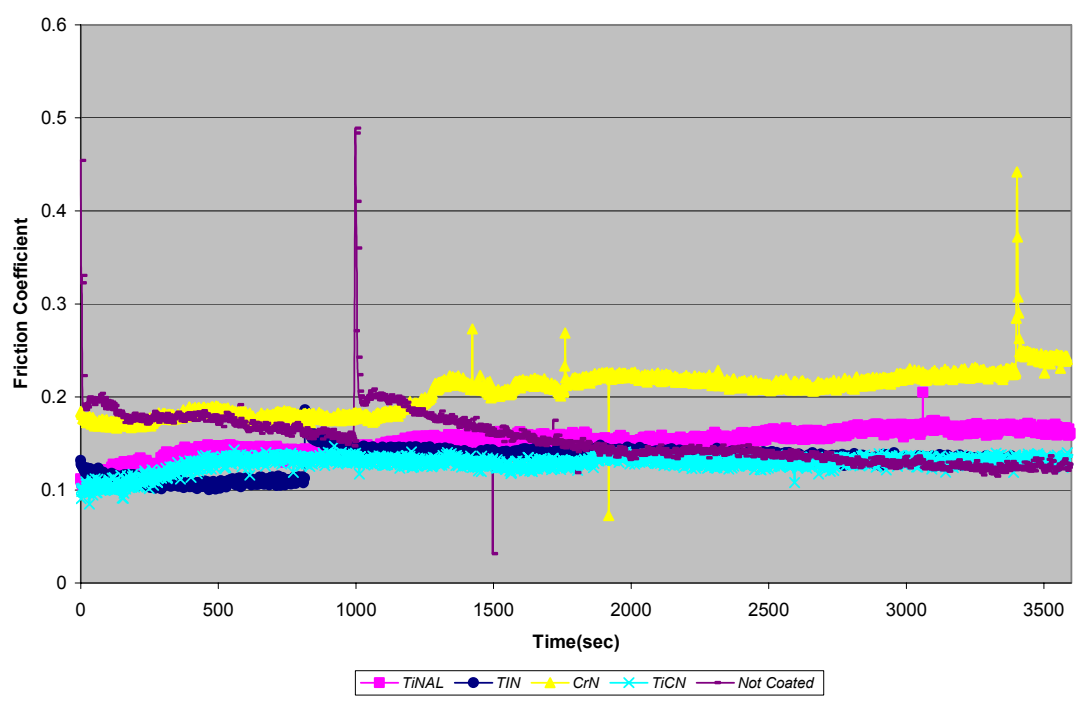

Figure 2: Variation of friction coefficient with time during wear test 


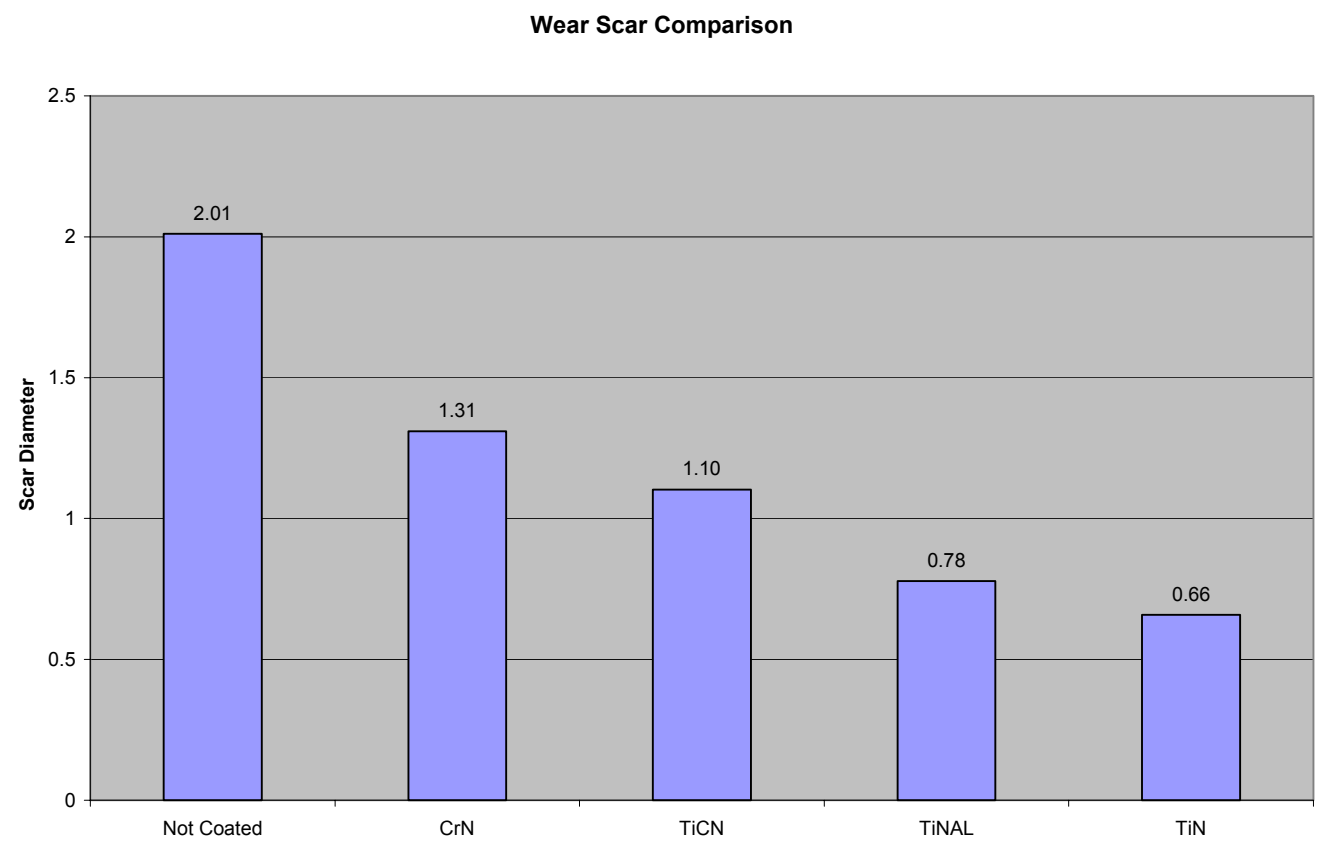

Figure 3: Average wear scar diameter ( $\mathrm{mm})$ for materials tested. 


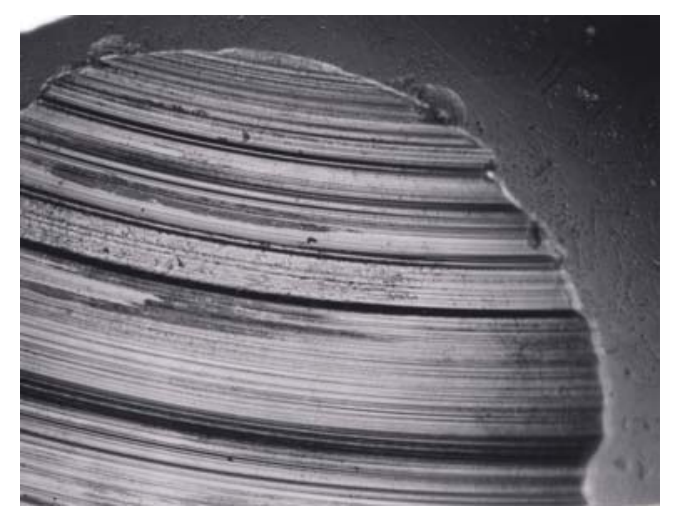

(a)

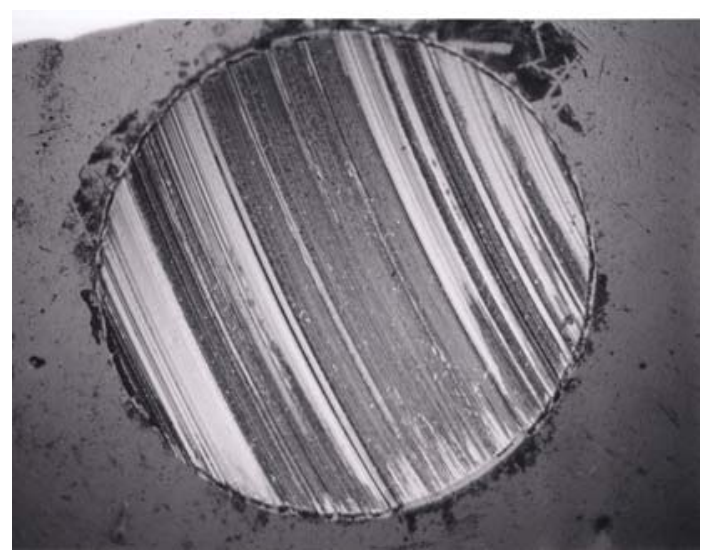

(c)

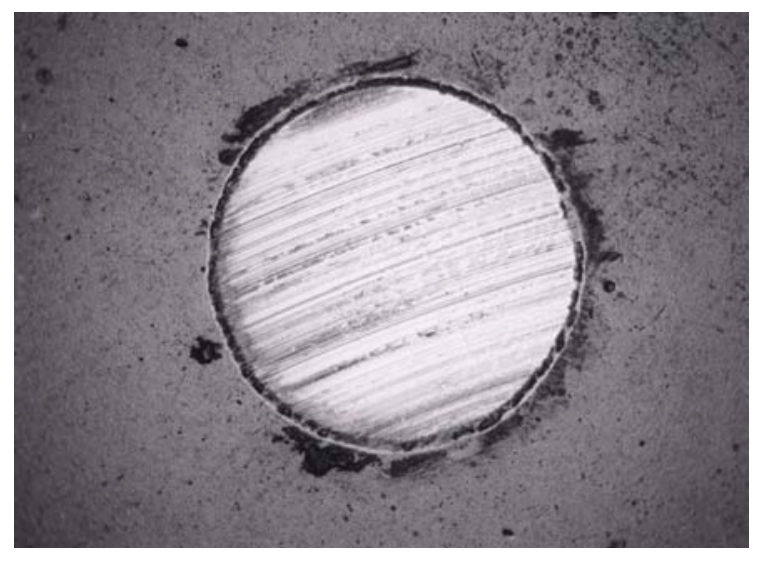

(b)

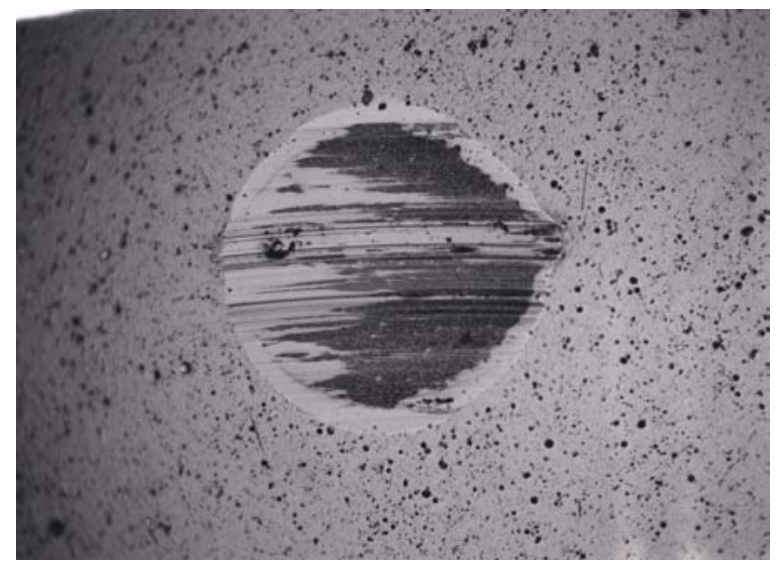

(d)

Figure 4: Optical micrograph of wear scar on stationary balls - all at the same magnification

(a) uncoated M50 ball, (b) TiAlN coated, (c) TiCN coated, (d) TiN coated 
